\title{
CIBERSEGURIDAD: CÓMO ADOPTAR MEDIDAS PARA PROTEGER SUS ACTIVOS DE INFORMACIÓN
}

\section{CYBERSECURITY: HOW TO TAKE MEASURES TO PROTECT YOUR INFORMATION ASSETS}

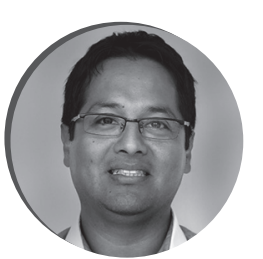

\author{
Jimmy A. Armas \\ ORCID:0000-0002-1176-8969 \\ Profesor de Business Intelligence and Predictability \\ Dirección de Computación e Informática \\ Facultad de Ingeniería, UPC \\ Lima - Perú \\ jimmy.armas@upc.pe
}

Recibido: 16 de noviembre de 2018

Aprobado: 23 de noviembre de 2018

Cómo citar este artículo:

Armas, J. (2018). Ciberseguridad: cómo adoptar medidas para proteger sus

activos de información. Review of Global Management, 4(2), 20-21.

Con la implementación de las nuevas tendencias y el impacto de la digitalización, el almacenamiento masivo de datos constituye un objetivo atractivo para los atacantes cibernéticos. Esto obliga a las organizaciones a replantear y proteger los procesos tecnológicos desde una perspectiva de ciberseguridad. Es importante conocer cuáles son estas amenazas y cuáles son los pasos básicos para reducir el riesgo de ser víctimas de un delito cibernético.

Palabras clave: ciberataque, ciberseguridad, seguridad informática.

With the implementation of new trends and the impact of digitization, mass data storage represents an appealing target for cyber attackers. This forces organizations to rethink and protect technological processes from a cybersecurity perspective. It is important to know what these threats are, and the basic steps to reduce the risk of being victims of a cyberattack

Keywords: cyberattack, cybersegurity, Informatic security.

E

n las últimas décadas, la tecnología ha facilitado el desarrollo de nuevos modelos de negocio y formas de brindar soluciones utilizando la información, convirtiéndose así en un activo importante de las empresas. En esta nueva realidad, las empresas

deben adoptar medidas para proteger sus activos y así evitar que terceros puedan cometer delitos y fraudes financieros, con lo que se generaría un nuevo entorno de amenazas creciente, con efectos devastadores en la continuidad operativa de los negocios. Según la Information Systems Audit and Control Association (ISACA), "la ciberseguridad es la protección de activos de información a través del tratamiento de amenazas que ponen en riesgo la información que es procesada, almacenada y transportada por lossistemas de información que se encuentran interconectados".

La ciberseguridad implica que las empresas tengan una actitud preventiva y proactiva para evitar

graves consecuencias. Por ello, se recomienda mejorar la seguridad dentro de la organización de acuerdo

con los siguientes pasos, que puedan reducir significativamente las posibilidades de que la empresa sea víctima de un delito cibernético: 1) realizar copias de seguridad periódica de los datos importantes, considerando herramientas de almacenamiento cloud; 2) proteger la organización de software malicioso, instalando antivirus y adoptando técnicas de protección; y 3) elaborar directrices deseguridad que puedan ser aplicadas por los empleados, ya que en muchos casos 
los incidentes no son provocados por ciberataques, sino que son los propios empleados quienes, bien por falta de conocimiento, bien por poco cuidado, ponen en peligro a la empresa.

Con la implementación de las nuevas tendencias y el impacto de la digitalización, la ciberseguridad cada día cobra más peso estratégico en las organizaciones. Esto obliga a replantear y proteger los procesos tecnológicos de las empresas, ya que con la Internet están expuestas a numerosas amenazas cibernéticas.

¿Cuáles son las amenazas que ponen en riesgo a las empresas?

He aquí cuatro de ellas:

• Hackers: "Ciberdelincuentes" que adoptan rápidamente nuevas estrategias para atacar a las empresas. Tratan de buscar cierta información de los usuarios a través de dispositivos móviles.

- Malware: Programas maliciosos que se instalan en las bases de datos de las empresas y pueden hacer colapsar el funcionamiento de las computadoras o dispositivos móviles, utilizándolos para monitorear y controlar la actividad privada en la Internet.

- Errores de programación: una mala programación puede poner en peligro los sistemas operativos y las aplicaciones de la empresa, logrando el desequilibrio de algunos datos

o acciones en la Internet.

- Fallos electrónicos, siniestros o catástrofes que, por razones externas, perjudican la información de los usuarios.

Es un error pensar que los ataques informáticos únicamente van dirigidos contra grandes compañías u órganos gubernamentales. Cualquier individuo y empresa puede ser el objetivo de los ciberdelincuentes.

Es importante que las empresas presten atención a los diferentes tipos de ataques cibernéticos. No sólo están en juego sus datos, sino que ser víctima de estos ataques también puede generar una mala reputación, hasta multas, demandas o una desvalorización de la compañía como resultado de la pérdida de confianza de la sociedad por los productos o servicios ofrecidos al cliente.

\section{Referencias:}

- Viewnext (21/02/2018). Tipos de seguridad informática. Recuperado de https://www.viewnext.com/tipos-de-seguridadinformatica/

- $\operatorname{INCIBE}(22 / 07 / 2018)$. La ciberseguridad en la Industria 4.0. Recuperado de https://www.incibe-cert.es/blog/ciberseguridadindustria-4-0

- PWC (2016). Informe Temas Candentes de la Ciberseguridad. Recuperado de http://www.pwc.es/es/publicaciones/gestionempresarial/temas-candentes-ciberseguridad.html 